detract from its ultimate mystery". Vitalism as biological metaphor survived for so long, she says, because it provided a basis for retaining our primary experience of life as a mystery at the same time that we decompose the mystery through scientific analysis.

Holding these two ideas together may be seen as a form of cognitive dissonance, a state of mind producing considerable discomfort and mental disorder. Allegiance to our current metaphor - 'life is a machine' - has led to much progress in medicine and agriculture, for example, but also caused great harm to human beings and the worldwide environment.

Many formal mathematical and other scientific arguments deny the machine model in biology, and it might be a good start to reveal these arguments to our students more than we do now.

We could start, perhaps, with Niels Bohr's worry that "the minimum freedom we must allow the organism will be just large enough to permit it, so to say, to hide its secrets from us"1, and end with Diethard Tautz's treatment of a biological equation equivalent to Heisenberg's uncertainty relationship in physics suggesting that attempts to predict biological function from genetic information may require "experiment on an evolutionary scale".

Our inclination to believe in life's ultimate mystery appears to have a declining vitalistic (or any other) force in the machine world of everyday life. Gupta does a real service in reminding us how important metaphor is in science. Just perhaps, we could find something closer to our primary experience of life than our current machine metaphor as we approach the analysis of living things.

A little bit of scientific philosophy and physical theory like this might, if not vitalize, then at least brighten up those deterministic lectures in Molecular Biology 101.

\section{Richard Strohman}

Department of Molecular and Cell Biology, University of California at Berkeley, 229 Stanley Hall, Berkeley, California 94720-3206, USA

1. Bohr, N. Nature 131, 458 (1933).

2. Tautz, D. Trends Genet. 16, 475-477 (2000).

\section{Ecology needs theory as well as practice}

Sir - In his Millennium Essay (Nature 408, 293; 2000), Jim Smith proposes that ecological theory is generally untestable, and therefore that ecology should concentrate less on theoretical explanation and more on finding applied solutions to humankind's environmental problems.
Although his concern for solving environmental problems is widely shared by theoretical and empirical ecologists alike, Smith's call for use of Robert Peters's 'predictive ecology' in place of a more conceptually grounded approach runs the risk of leading ecology into a dead end of blind empiricism.

Smith overstates Karl Popper's influence over the philosophy of science. Science is a much broader and less formally rigorous enterprise than Popper envisioned. In The Structure of Scientific Revolutions (University of Chicago Press, Chicago, 1970) Thomas Kuhn, for example, argued that a large component of cultural subjectivity determines the outcome of the scientific enterprise. His concept of paradigm shifts implicitly assumes that political interactions among scientists are at least as important as empirical verification of hypotheses in deciding the outcome of scientific progress. Science can still uncover much about the natural world, even if it is such a culturally dominated social system. Neither Popper's views nor a less restrictive philosophy of science justifies the abandonment of conceptual work in ecology.

Progress in ecology has been hampered in the past by assuming that complex ecological systems can be adequately described by relatively simple linearized models, but even those who originated this approach realized its limited usefulness. Significant advances in science are not based solely on the success of a model in predicting some unknown phenomenon.

Smith's example of relativity is a case in point. The real significance of relativity to physics was not its ability to predict the bending of light by large, massive celestial bodies. Rather, relativity revolutionized physics by revealing an underlying conceptual unity to disparate phenomena. Relativity did not supplant classical physics, it simply limited the spatial and temporal scales to which the rich theoretical framework of classical physics could be applied with acceptable precision.

Ecology will make real scientific progress only by developing a rigorous conceptual framework that can be tested with appropriately sophisticated statistical methodology. Ecological systems are indeed complex. Simplistic semi-empirical relationships based on vague, poorly parameterized, linear statistical models of single systems provide only approximate or temporary solutions to environmental problems. They do not determine which problems are of greatest importance or how limited resources might be optimally allocated.

Only a larger, more comprehensive conceptual framework can provide such guidance. Explorations of ecological theory are nice work and are essential to the progress of ecology as science.

\section{Brian A. Maurer}

Department of Fisheries \& Wildlife and

Department of Geography, Michigan State

University, East Lansing, Michigan 48824, USA

\section{Pressure to meet current needs hinders science}

Sir-Your report (Nature 407, 276; 2000) about the World Bank giving higher priority to science was a welcome reminder that, unfortunately, national and international 'development' organizations have given short shrift to the scientific and technological base that is essential to enable countries to prosper.

In December 1992, former US president Jimmy Carter and I, with a distinguished task force from the Carnegie Commission on Science, Technology and Government, released a report entitled "Partnerships for Global Development: The Clearing Horizon". We underscored the critical importance of science and technology in economic development along with the imperative for global cooperation.

During the 1990s, however, major donors yielded to pressure to use almost all aid resources for distributing food and medicine today instead of improving agricultural productivity and vaccines for tomorrow. Further, developed countries suffered 'aid fatigue' because foreign assistance seemed to be a perpetual handout rather than a catalyst for economic independence. Investment in science and education was also marginalized by grave difficulties in creating financial stability with honest, democratic governance under the rule of law.

US secretary of state Madeleine Albright, seeing a growing need for science and perhaps sensing the new rustlings at the bank, recently named a science adviser: Norman Neureiter, a chemist with an extraordinarily sophisticated understanding of how universities and the private sector interact with the public sector to spark economic growth. This long-needed graft of science onto US diplomacy will demand intensive care for many months.

Along similar lines, don't expect a quick turnaround from the World Bank's higher priority on science. The bank will have to rethink its mission and operations to decide how global technological change meshes with its economic strategy.

Rodney W. Nichols

New York Academy of Sciences, 2 East 63rd Street, New York, New York 10021, USA 